Jumpell par

http://jurnal.bhmm.ac.id/index.php/jpkm/index

Corresponding Author.

email address : afi.machsuni@gmail.com (Afi Lutfiyati)

Julia Pertiwi

Received :7 Agustus 2020

Revised : 27 Agustus 2020

Accepted : 13 September 2020

\title{
Dukungan Keluarga dan Keputusan Inisiasi Hemodialisis Pasien Gagal Ginjal Kronik di RSUD Kota Madiun Julia Pertiwi ${ }^{1}$
}

\author{
${ }^{1 *}$ Prodi Rekam Medis dan Informasi Kesehatan \\ Universitas Veteran Bangun Nusantara \\ pertiwijulia26@gmail.com
}

\begin{abstract}
ABSTRAK
Data Badan Kesehatan Dunia atau World Health Organization (WHO) memperlihatkan yang menderita gagal ginjal baik akut maupun kronik mencapai 50\% sedangkan yang diketahui dan mendapatkan pengobat 7 an hanya $25 \%$ dan $12,5 \%$ yang terobati dengan baik. Penelitian ini untuk mengetahui hubungan dukungan keluarga dengan keputusan inisiasi hemodialisis pada pasien gagal ginjal kronik di ruang hemodialisa RSUD Kota MadiunTeknik sampling yang digunakan yaitu purposive sampling dengan jumlah 47 sampel. Pengumpulan data dilakukan dengan menggunakan kuesioner. Pengolahan data dengan uji chi-square didapatkan $(\alpha=0,05)$. Hasil penelitian menunjukkan jumlah responden dengan dukungan keluarga mendukung keputusan inisiasi terdapat $26(55,3 \%)$ responden dan yang tidak menunda keputusan inisiasi hemodialisis terdapat $17(36,2 \%)$ responden sedangkan responden dengan dukungan keluarga kurang $2(4,3 \%)$ responden dan yang menunda keputusan inisiasi hemodialisis terdapat $2(4,3 \%)$ responden dan didapatkan nilai $\rho$ value $=0,000$. Kesimpulan ini menunjukkan ada hubungan dukungan keluarga dengan keputusan inisiasi hemodialisis di Ruang Hemodialisa pada responden di ruang hemodialisa RSUD Kota Madiun.
\end{abstract}

Kata kunci : Dukungan Keluarga, Keputusan Inisiasi Hemodialisis, Pasien Gagal Ginjal Kronik.

\section{ABSTRACT}

Data from the World Health Organization (WHO) showed that those who suffer from kidney failure both acute and chronic reach $50 \%$ while those who were known and get treatment wereonly $25 \%$ and $12.5 \%$ are treated well. In this study, the researcher uses purposive sampling with 47 samples. Data was collected by questionnaire. Analyzed data by chi-square test obtained $(\alpha=0.05)$. The results showed the number of respondents with family support were supported the initiation decision, there were 26 $(55.3 \%)$ respondents and those who did not postpone the decision on hemodialysis initiation were 17 $(36.2 \%)$ respondents while the respondents with less family support $2(4.3 \%)$ respondents and those who postpone the decision on hemodialysis initiation are $2(4.3 \%)$ respondents and the value $\rho$ value $=$ 0.000 .

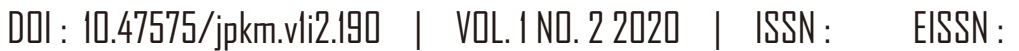


This conclusion shows that there is a corelation between family support and the decision on hemodialysis initiation in the Hemodialysis Room in respondents by the hemodialysis room at the Kota Madiun Hospital, increasingly supporting the quicker decision to initiate.

Keywords : Family Support, Decision on Hemodialysis Initiation, Patients with Chronic Kidney

\section{PENDAHULUAN}

Gagal ginjal kronik (GGK) merupakan penyakit yang terjadi setelah berbagai macam penyakit yang merusak masa nefron ginjal sampai pada titik keduanya tidak mampu untuk menjalankan fungsi regulatorik dan ekstetoriknya untuk mempertahankan homeostatis.Gagal ginjal kronik secara progresif kehilangan fungsi ginjal nefronnya satu persatu yang secara bertahap menurunkan keseluruhan fungsi ginjal (Lukman, 2013).

Dukungan keluarga merupakan salah satu faktor yang mempengaruhi keputusan inisisasi hemodialisis. Hemodialisis merupakan terapi bagi penderita penyakit ginjal kronik yang membutuhkan biaya besar, tidak cukup dalam waktu 1-2 bulan saja tetapi butuh waktu yang lama. Penderita tidak bias melakukan terapi hemodialisis sendiri, mengantar ke pusat hemodialisis dan melakukan kontrol ke dokter. Tanpa adanya dukungan keluarga mustahil program terapi hemodialisis bias dilakukan sesuai jadwal (Sunarni, 2009).

Data Badan Kesehatan Dunia atau World Health Organization (WHO) memperlihatkan yang menderita gagal ginjal baik akut maupun kronik mencapai 50\% sedangkan yang diketahui dan mendapatkan pengobatan hanya $25 \%$ dan $12,5 \%$ yang terobati dengan baik (Indrasari, 2015).

Riset Kesehatan Dasar (Riskesdas) tahun 2013 menunjukkan prevalensi gagal injal kronis berdasarkan diagnosis dokter di Indonesia 0,2\%. Prevalansi tertinggi di Sulawesi Tengah sebesar 0,5\% diikuti Aceh, Gorontalo, dan Sulawesi Utara masaing-masing 0,4\%. Sementara Nusa Tenggara Timur, Sulawesi Selatan, Lampung, Jawa Barat, Jawa Tengah, Jawa Timur masing-masing 0,3\%.

Penyakit gagal ginjal kronik menjadi suatu fenomena di Negara maju dan berkembang.Di Indonesia penyakit gagal ginjal kronik merupakan masalah yang besar.Insiden ini diperkirakan sekitar 40-60 kasus perjuta penduduk pertahun (Suwitra, 2014). Survey Perhimpunan Nefrologi Indonesia menunjukkan 12,5\% dari populasi mengalami penurunan fungsi ginjal (Adriyana, 2011). Berdasarkan survey oleh Prodjosudjadi et al, angka insidensi pasien GGK sebesar 30,7 / juta penduduk di Indonesia dan angka prevalensinya sebesar 23,4/juta penduduk.

Dari data 7 tahun Indonesia Renal Registery (2015) jumlah pasien gagal ginjal kronik yang menjalani hemodialisa pada tahun 2015 di Indonesia diperkirakan 30,554 orang. Dengan jumlah kematian sebanyak 1.243 orang yang diperkirakan lama hidup dengan HD adalah 6-12 bulan.

Berdasarkan studi pendahuluan yang dilakukan peneliti di RSUD Kota Madiun pada tahun 2018 didapatkan data pasien rawat inap dan rawat jalan gagal ginjal kronik sebanyak 3.317. Data yang diperoleh dari data Administrasi ruang Hemodialisis RSUD Kota Madiun pada tahun 2018 terhitung bulan Oktober sampai Desember terdapat sekitar 784 pasien hemodialisis yang melakukan hemodialisis seminggu $2 \mathrm{x}$ secara rutin.

Terapi Hemodialisis ini cukup efektif, walaupun angka kesakitan dan kematian pasien masih tinggi. Di Amerika Serikat pelaksanaan hemodialisis mencapai 66\% pasien gagal ginjal, sedangkan di Eropa mencapai 46\% - 98\% pasien menjalani hemodialisa (Vassalotti et al, 2006).

Keputusan program inisiasi hemodialisis dapat dipengaruhi oleh berbagai faktor. Beberapa faktor yang diprediksi dapat mempengaruhi keputusan inisiasi hemodialisis diantaranya yaitu faktor demografi yang meliputi umur, jenis kelamin, status pendidikan dan status pekerjaan, faktor geografi yang meliputi jarak antara tempat tinggal dengan tempat pelayanan kesehatan, faktor sosial yaitu dukungan yang diberikan kepada pasien dari keluarga dan orang-orang yang dekat dengan pasien, faktor ekonomi meliputi pendapatan penghasilan bulanan dan status asuransi, serta faktor biologis meliputi penyakit penyebab gagal ginjal dan informasi nilai laboratorium yang meliputi nilai LFG dan kreatinin (Benner Hellen, 2006; Dogan et al, 2008; Shaefer \& Rohrich (1999); Obrador et al, 1999; Kausz et al, 2000; Busuioc et al, 2008; Wilson, 2006; Ledebo et al, 2001) Faktor dukungan pelayanan kesehatan (Dixon et al, 2011; Emergency Nurse, 2011). 
Dukungan kepada pasien yang baik dari berbagai faktor dapat mempengaruhi pasien dalam mengambil keputusan inisiasi hemodialisis sebagai modalitas pengobatan yang akan dijalani. Peran petugas kesehatan termasuk di dalamnya perawat sebagai pemberi pelayanan kesehatan, edukator dan konselor memberikan pengaruh terhadap pasien dalam menentukan keputusan untuk penatalaksanaan penyakitnya

\section{METODE PENELITIAN}

Desain penelitian ini menggunakan cross-sectional. Sampel dalam penelitian ini diambil dengan teknik purposive sampling. Penelitian ini dilaksanakan di Ruang Hemodialisa RSUD Kota Madiun pada tanggal 20 Mei-31 Mei 2019. Pengumpulan data dilakukan dengan membagikan kuesioner yang terdiri dari kuesioner dukungan keluarga dan keputusan inisasi.

Populasi pada penelitian ini adalah seluruh pasien GGK yang menjalani terapi hemodialisis di Ruang Hemodialisa. Sampel yang digunakan dalam penelitian ini berjumlah 47 orang pasien GGK yang menjalani HD. Kriteria Inklusi : Pasien GGK, bersedia menjadi responden, mampu berkomunikasi verbal, fungsi kognitif baik, pasien menjalani hemodialisis tidak lebih dari 1 bulan. Kriteria Eksklusinya yakni : Pasien tidak kooperatif, pasien yang mengalami gangguan kesehatan, penurunan kesadaran saat pengambilan data. Variabel dependen dalam penelitian ini yaitu

\section{HASIL}

\section{Dukungan Keluarga}

Tabel 1.

Dukungan keluarga pada klien gagal ginjal kronik di ruang Hemodialisa RSUD Kota Madiun

\begin{tabular}{|l|c|c|}
\hline \multicolumn{1}{|c|}{ Dukungan keluarga } & Frekuensi & $\begin{array}{c}\text { Presentase } \\
\text { (\%) }\end{array}$ \\
\hline Mendukung & 30 & 63.8 \\
\hline Tidak Mendukung & 17 & 36.2 \\
\hline Jumlah & 47 & 100.0 \\
\hline
\end{tabular}

Sumber : Data primer penelitian tahun 2019

Berdasarkan tabel 1. diketahui bahwa dukungan keluarga pada pasien gagal ginjal kronik di Ruang Hemodialisa RSUD Kota Madiun dari 47 responden yang diteliti, sebagian besar dengan dukungan keluarga yang mendukung sebanyak 30 responden $(63,8 \%)$.

Tabel 2.

Parameter dukungan keluarga pada klien gagal ginjal kronik di ruang Hemodialisa RSUD Kota Madiun

\begin{tabular}{|c|l|c|c|}
\hline No & \multicolumn{1}{|c|}{ Parameter } & $\begin{array}{c}\text { Mendukung } \\
\text { (\%) }\end{array}$ & $\begin{array}{c}\text { Tidak } \\
\text { Mendukung } \\
(\%)\end{array}$ \\
\hline 1 & Dukungan Emosional & 76,2 & 23,7 \\
\hline 2 & Dukungan Informasi & 90,8 & 9,1 \\
\hline 3 & Dukungan Instrumen & 86,5 & 13,4 \\
\hline 4 & Dukungan Penghargaan & 89,7 & 10,2 \\
\hline
\end{tabular}

Sumber : Data primer penelitian tahun 2019

Berdasarkan tabel 2. diketahui hasil penelitian parameter dukungan keluarga sebagian besar dengan dukungan keluarga informasi yang mendukung sebanyak 90,8\% dan sebagian kecil dengan dukungan keluarga Emosional yang tidak mendukung sebanyak 76,2\%. 


\section{Keputusan Inisiasi Hemodialisis}

Tabel 3.

Keputusan inisiasi hemodialisis pada klien gagal ginjal kronik di Ruang Hemodialisa RSUD Kota Madiun

\begin{tabular}{|c|c|c|}
\hline Inisiasi Hemodialisis & Frekuensi & $\begin{array}{c}\text { Presentasi } \\
\text { (\%) }\end{array}$ \\
\hline Langsung & 28 & 59,6 \\
\hline Menunda & 19 & 40,4 \\
\hline Jumlah & 47 & 100,0 \\
\hline
\end{tabular}

Sumber : Data dari hasil pengolahan data observasi

Berdasarkan tabel 3. dapat diketahui bahwa dari 47 responden yang diteliti, sebagian besar dengan inisiasi langsung sebanyak 28 reponden $(59,6 \%)$.

3. Hubungan Dukungan Keluarga Dengan Keputusan Inisiasi Hemodialisis pada Pasien Gagal Ginjal Kronik di Ruang Hemodialisa RSUD Kota Madiun Tahun 2019

Tabel 4.

Crosstabulation hubungan dukungan keluarga dengan keputusan inisiasi hemodialisis pada pasien gagal ginjal kronik di ruang hemodialisa RSUD Kota Madiun.

\begin{tabular}{|c|c|c|c|c|c|c|}
\hline \multirow{2}{*}{} & \multicolumn{6}{|c|}{ Keputusan Inisiasi } \\
\cline { 2 - 7 } & \multicolumn{2}{|c|}{ Langsung } & \multicolumn{2}{c|}{ Menunda } & \multicolumn{2}{c|}{ Total } \\
\hline Dukungan Keluarga & $\mathrm{N}$ & $\%$ & $\mathrm{~N}$ & $\%$ & $\mathrm{~N}$ & $\%$ \\
\hline Mendukung & 26 & 86,7 & 4 & 13,3 & 30 & 100 \\
\hline Tidak mendukung & 2 & 11,8 & 15 & 88,2 & 17 & 100 \\
\hline Total & 28 & 59,6 & 19 & 40,4 & 47 & 100 \\
\hline$\alpha=0,05$ & \multicolumn{7}{|c|}{$\rho$ value $=0,000$} \\
\hline
\end{tabular}

Sumber : Data dari hasil pengolahan data observasi

Berdasarkan tabel 4. diatas diketahui crosstabulation pada dukungan keluarga yang mendukung sejumlah 30, sebanyak 26 responden $(86,7 \%)$ memberikan keputusan inisiasi langsung dan 4 responden $(13,3 \%)$ menunda keputusan inisiasi. Pada responden yang dukungan keluarga dengan kategori tidak mendukung sejumlah 17 , sebanyak 15 responden $(88,2 \%)$ menunda keputusan inisiasi dan 2 responden $(11,8 \%)$ melakukan inisiasi langsung.

Hasil uji statistik menunjukkan bahwa nilai $\rho$ value $=0,000, \mathrm{H} 0$ ditolak $\mathrm{H} 1$ diterima artinya ada hubungan dukungan keluarga dengan keputusan inisiasi hemodialisis pada responden di ruang hemodialisa RSUD Kota Madiun semakin mendukung semakin cepat melakukan keputusan inisiasi dengan keeratan tingkat sedang $(0,591)$.

\section{PEMBAHASAN}

\section{Dukungan Keluarga Pada Pasien Gagal Ginjal Kronik Di Ruang Hemodialisa RSUD Kota Madiun}

Hasil analisis di ruang hemodialisa RSUD Kota Madiun menunjukkan bahwa dukungan keluarga kepada pasien saat mengambil keputusan inisiasi hemodialisis baik dengan sebagian besar dukungan keluarga yang mendukung sebanyak 30 pasien (63,8\%). McClellan, (1993) menyebutkan sumber dukungan sosial dapat berasal dari pasangan hidup, orang tua, saudara, anak, kerabat, teman, rekan kerja, staf medis dan kelompok masyarakat yang ada di sekitar pasien. Bila melihat hasil analisis mayoritas sebanyak 30 pasien $(63,8 \%)$ adalah menikah, menunjukkan bahwa pasien mempunyai orang terdekat sebagai sumber dukungan sosialnya.

Berdasarkan informasi saat penelitian, pasien mengatakan bahwa keluarga mencarikan informasi yang dibutuhkan terkait penatalaksanaan penyakit pasien ini. Hal ini sesuai dengan bentuk dukungan Infomational support/ dukungan informasi yang diberikan keluarga. 
Hasil dari parameter dukungan keluarga di ruang hemodialisa RSUD Kota Madiun menunjukkan bahwa sebagian besar yang mendukung 90,8\% mendapatkan dukungan informasi. Menurut peneliti, dukungan informasi sangat mempengaruhi dalam bentuk dukungan informasi yaitu dukungan dengan memberikan saran dan informasi yang dibutuhkan pasien saat pasien menghadapi dan memecahkan masalah serta companionship support adalah dukungan pada pasien gagal ginjal kronik yang akan menjalani inisiasi hemodialisis dalam bentuk kebersamaan, sehingga pasien merasa sebagai bagian dari keluarga.

Bentuk dukungan lain dari esteem support / dukungan penghargaan yaitu pemberian dukungan ataupun persetujuan terhadap ide keputusan modalitas pengobatan yang akan dijalani pasien.

Hal ini didukung oleh penelitian McClellan (1993) menyebutkan bahwa pasien yang mendapatkan dukungan dari orang-orang terdekat akan membuat pasien mampu menunjukkan perilaku positif saat mengalami stress akibat didiagnosis gagal ginjal dan harus melakukan hemodialisis serta meningkatkan percaya diri pasien dalam mengambil keputusan untuk memulai hemodialisis.

Hasil presentase dukungan keluarga informasi di ruang hemodialisa RSUD Kota Madiun menunjukkan bahwa terdapat $26,5 \%$ pasien mendapatkan dukungan penghargaan dengan dukungan pasangan hidup membuat pasien dapat bertingkah laku positif saat menghadapi stress, mampu mengambil strategi yang tepat saat menghadapi masalah sehingga secara tidak langsung dukungan pasangan hidup mampu menghilangkan efek negatif dari stress yang dialami.

\section{Keputusan Inisiasi Pada Pasien Gagal Ginjal Kronik Di Ruang Hemodialisa RSUD Kota Madiun}

Inisiasi hemodialisis adalah proses dimulainya hemodialisis sebagai terapi pengganti ginjal yang dilakukan pada pasien gagal ginjal kronik (PERNEFRI, 2003). Keputusan inisiasi hemodialisis dipengaruhi oleh banyak faktor, baik dari individu pasien itu sendiri ataupun faktor lain.

Hasil analisis penelitian di ruang hemodialisa RSUD Kota Madiun menunjukkan bahwa 28 pasien $(59,6 \%)$ mengambil keputusan tidak menunda inisiasi hemodialisis setelah pasien didiagnosis gagal ginjal kronik. Sedangkan 19 pasien (40,4\%) menunda melakukan inisiasi hemodialisis setelah didiagnosis gagal ginjal. Angka 40,4\% pasien yang menunda keputusan untuk inisiasi hemodialisis menurut peneliti masih tinggi.

Setelah dilakukan Crosstabulation didapatkan tujuh faktor yang berpengaruh terhadap pengambilan keputusan pasien inisiasi hemodialisis diantaranya yaitu usia, jenis kelamin, pendidikan, pekerjaan, pendapatan, asuransi, nilai LFG.

Sedangkan setelah dilakukan Crosstabulation didapatkan lima faktor yang berpengaruh terhadap pengambilan keputusan inisiasi hemodialisis yaitu usia, jenis kelamin, pekerjaan, asuransi, nilai LFG. Pasien yang tidak menggunakan asuransi sebanyak $66,7 \%$ yang menunjukkan bahwa pasien yang tidak memiliki asuransi beresiko untuk menunda inisiasi $66,7 \%$ kali lebih besar dibandingkan dengan pasien yang memiliki asuransi setelah dikontrol oleh variabel nilai LFG. Sedangkan LFG pasien 1,73 yang berarti bahwa pasien yang mempunyai LFG tinggi beresiko menunda inisiasi hemodialisis sebesar 1,73 kali lebih besar dibandingkan dengan pasien yang memiliki LFG yang lebih rendah setelah dikontrol oleh variabel status asuransi.

Melihat hasil penelitian yang menunjukkan bahwa 60\% pasien mengambil keputusan tidak menunda inisiasi hemodialisis setelah didiagnosis gagal ginjal tahap akhir, dengan mayoritas pasien $38,8 \%$ bekerja sebagai swasta, serta berpendapatan dibawah UMR $(51,1 \%)$ membuktikan bahwa asuransi merupakan faktor yang berpegaruh terhadap keputusan pasien melakukan inisiasi hemodialisis.

Sementara LFG merupakan faktor yang berpengaruh juga terhadap inisiasi hemodialisis. Laju Filtrasi Glomerulus adalah kemampuan glomerulus dalam memfiltrasi darah. Nilai normal untuk LFG adalah 90-135 ml/mnt (Kallenbach, 2005). Pasien dengan LFG tinggi cenderung menunda hemodialisis, secara fisiologis LFG tinggi, tubuh masih mampu beradaptasi dengan perubahan penurunan LFG. 
Dalam penelitian ini pasien yang mempunyai LFG relative tinggi cenderung untuk menunda hemodialisis dibandingkan denganpasien dengan LFG rendah. Hal ini tidak sesuai dengan pendapat Ledebo et al, (2001) yang menyebutkan bahawa penanganan yang tepat dan cepat pada pasien dengan LFG kurang dari $15 \mathrm{ml} / \mathrm{mnt}$, akan dapat memperlambat bahkan menghentikan penurunan fungsi ginjal. Sedangkan Roina \& Megawati, (2010), menyebutkan bahwa ada faktor lain yang mempengaruhi penurunan Laju Filtrasi Glomerulus seseorang yaitu usia. Disebutkan bahwa pada usia 40 tahun maka secara fisiologis akan terjadi pengurangan LFG sebanyak 10\% setiap tahun, hingga usia 80 tahun.

\section{Hubungan Dukungan Keluarga Dengan Keputusan Inisiasi Hemodialisis Pada Pasien Gagal Ginjal Kronik Di Ruang Hemodialisa RSUD Kota Madiun}

Hasil uji statistik menunjukkan bahwa nilai $\rho$ value $=0,000, \mathrm{H} 0$ ditolak $\mathrm{H} 1$ diterima artinya ada hubungan dukungan keluarga dengan keputusan inisiasi hemodialisis pada responden di ruang hemodialisa RSUD Kota Madiun semakin mendukung semakin, cepat melakukan keputusan inisiasi dengan keeratan tingkat sedang $(0,591)$.

Pada dukungan keluarga secara signifikan mempengaruhi pasien dalam keputusan inisiasi hemodialisis dengan $\rho$ value $=0,000$. McClellan, (1993) menyebutkan sumber dukungan sosial dapat berasal dari pasangan hidup, orang tua, saudara, anak, kerabat, teman, rekan kerja, staf medis dan kelompok masyarakat yang ada di sekitar pasien. Bila melihat hasil analisis mayoritas sebanyak 30 pasien $(63,8 \%)$ adalah menikah, menunjukkan bahwa pasien mempunyai orang terdekat sebagai sumber dukungan sosialnya.

Dalam penelitian ini, peneliti menggali dukungan sosial dari keluarga secara tersendiri, dengan alasan bahwa peneliti berpendapat dukungan keluarga merupakan faktor penting terhadap pelaksanaan pengambilan keputusan inisiasi hemodialisis. Pasien akan merasa berarti bagi orang lain, harga diri meningkat serta tidak kehilangan identitas diri, walaupun pasien sakit dan memerlukan hemodialisis yang ajan dijalaninya sepanjang sisa hidupnya. Hal ini sesuai dengan hasil penelitian dari Baron \& Byrne, (2000) yang menyebutkan bahwa interaksi yang baik antara pasien dan keluarganya membuat pasien mampu mengembangkan kepribadiannya, menyadari posisi dirinya dalam hirarki sosial serta mampu menentukan identitas diri dan harga dirinya.

Hasil penelitian di ruang hemodialisa RSUD Kota madiun menunjukkan bahwa sebanyak 30 pasien $(63,8 \%)$ berstatus menikah. Menurut peneliti, dukungan pasangan hidup sangat mempengaruhi pasien dalam pengambilan keputusan terhadap modalitas pengobatan yang akan dijalani. Pasangan hidup dapat menjadi sumber koping yang adekuat dalam menghadapi stressor. Dukungan pasangan hidup mampu memberikan kenyamanan fisik dan psikologis saat pasien mengalami stress karena harus menjalani terapi hemodialisis. Ini membuktikan bahwa pasien masih merasa dicintai, diperhatikan, dihargai oleh pasangannya.

Selain itu kenyamanan fisik dan psikologis, dengan dukungan pasangan hidup membuat pasien dapat bertingkah laku positif saat menghadapi stress, mampu mengambil strategi yang tepat saat menghadapi masalah sehingga secara tidak langsung dukungan pasangan hidup mampu menghilangkan efek negatif dari stress yang dialami.

Hal ini didukung oleh penelitian McClellan (1993) menyebutkan bahwa pasien yang mendapatkan dukungan dari orang-orang terdekat akan membuat pasien mampu menunjukkan perilaku positif saat mengalami stress akibat didiagnosis gagal ginjal dan harus melakukan hemodialisis serta meningkatkan percaya diri pasien dalam mengambil keputusan untuk memulai hemodialisis.

\section{KESIMPULAN}

1. Dukungan keluarga pada klien gagal ginjal kronik di Ruang Hemodialisa RSUD Kota Madiun dari 47 responden sebagian besar yaitu 30 responden $(63,8 \%)$ termasuk kategori mendukung.

2. Persentase keputusan inisiasi yaitu 28 responden $(59,6 \%)$ langsung memutuskan inisiasi hemodialisis dan menunda keputusan inisiasi hemodialisis di Ruang Hemodialisa RSUD Kota Madiun. 
3. Ada hubungan dukungan keluarga dengan keputusan inisiasi hemodialisis di Ruang Hemodialisa pada responden di ruang hemodialisa RSUD Kota Madiun semakin mendukung semakin, cepat melakukan keputusan inisiasi.

\section{SARAN}

Beberapa manfaat penelitian yang sudah dipaparkan sebelumnya, maka peneliti memberikan saran kepada :

1. Institut Pendidikan

Bagi institut pendidikan diharapkan dapat menambah buku pustaka atau referensi tentang penyakit gagal ginjal kronik untuk menambah sumber dalam penelitian yang dilakukan mahasiswa.

2. Institut Rumah Sakit

Bagi RSUD Kota Madiun khususnya perawat di ruangan hemodialisa diharapkan lebih aktif lagi dalam memberikan bimbingan ataupun penyuluhan tentang pentingnya rutin dalam menjalankan cuci darah pada pasien gagal ginjal kronik agar hasil yang diharapkan lebih maksimal.

3. Bagi peneliti selanjutnya

Penelitian ini dapat dikembangkan oleh peneliti lain dengan mengubah metode penelitian, misalnya pengambilan data dilakukan saat pasien sedang tidak melakukan hemodialisa dengan keadaan kooperatif sehingga pasien dapat melakukan pengisian kuesioner lebih maksimal lagi. Selain itu dapat juga melakukan penelitian tentang dukungan keluarga dengan keputusan inisiasi hemodialisis pada pasien gagal ginjal kronik menggunakan audio visual dan pendidikan kesehatan dengan demonstrasi sehingga pasien HD tidak hanya melihat dan mendengarkan tetapi dapat mempraktekkan sendiri.

\section{DAFTAR PUSTAKA}

Arikunto, S. 2010. Prosedur Penelitian Suatu Pendekatan Praktek. Jakarta: Rineka Cipta.

Andarmoyo, Sulistyo. 2012. Keperawatan Keluarga Konsep Teori, proses Dan Praktik Keperawatan. Yogyakarta: GrahaIlmu.

Baradero, M. 2008. Klien Gangguan Ginjal Seri Asuhan Keperawatan. Jakarta: EGC.

Brenner H, 2006. The economics of dialysis, London, Ontario: CANNT 2006 in Patnership with RPN, London Convention Centre.

Brenner M.B., Lazarus.M.J. 2000. Acut Renal Failure, (3rd.ed). New York:Churchill Living Stone.

Burrows, M.L. 2008. Early dialysis/nephrology nursing and recollections of CANNT; The CANNT Journal, Voll.8, Issue 3.

Busuioc M, Tatomir P. G, Covic A. 2008. Dialysis or not in the very elderly ESRD patient, Romania: Int Urol Nephrol. 40: 1127-1132. DOI 10.1007/s11255-008-9435-7.

Daryani. T, 2011. Faktor - faktor yang mempengaruhikeputusaninisiasi dialysis pasiengagalginjaltahapakhir diRSUP DR. SOERDAJI TIRTONEGORO KLATEN. Tesis. FakultasIlmuKeperawatanUniversitas Indonesia. Diakses pada tanggal 19 Desember 2018.

Depkes RI. 2013. Laporan Nasional Riskesdas2013.Http://litbag.depkes.go.id/. Diakses pada tanggal 19 Desember 2018.

Dogan S, Ekiz S, Yucel L, Osturk S, Kazancioglu R. 2008. Relation of demographic, clinic and biochemical, parameters to peritonitis in peritoneal dialysis, Turkey: Journal of Renal Care 34(1), 5-8. 
Dixon J, Borden P, Kaneko T.M, ShoolwertzA.C. 2011. Multidisciplinary CKD areen.

Emergency Nurse. 2011. Caring for patients with kidney failure. Emergency Nurse. Marc 2011.vol 19.no10.

Friedman. L.M. 1998. Keperawatan Keluarga teori Dan Praktik. Edisi 4. Jakarta: EGC.

Friedman, L.M. 2010. Buku Ajar Keperawatan Keluarga. Jakarta: EGC.

Gerrish, M. 2005. Implementating nurse pres cribbing within the hemodialysis unit: EDTNA, ERCA journal, XXX13.

Ghafari A, Sepehrvand N, Hatami S, Ahmadnejad E, Ayubian B, Maghsudi R, Kargar C. Effect of an educational program on awareness about peritoneal dialysis among patiens on hemodialysis. Saudi Ginjal Transpl Dis J. 2010. 21:636-40.

Gomez, Valido, Celadilla, Quiros \& Mojon. 1999. Validity of a standart information protocol provided to End-Stage Renal Disease patients and is effect on treatment selection, Canada: Peritoneal Dialysis International. Vol 19,pp:471-477.

Harwood, Wilson, Heidenheim \& Lindsay. 2004. The advanced practice nurse-nephrologist care model: Effect on patient out comes and hemodialysis unit team satisfaction, Canada: International Society For Hemodialysis.

Henderson, S. 2004. The role of the clinical nurse specialist in medical-surgical nursing.

Ignatavicius \& Workman, M,L. 2006. Medical surgical nursing: critical thinking for collaborative care. 5 Edition. Elsevier Saunder. St.Louis Missouri.

Kallenbach et al. 2005. Review of hemodialysis for nursing and dialysis personnel 7 thEdition. Elsevier Saunders. St Louis Missouri.

Kausz A.T, Obrador G.T, Arora P, Ruthzazer R, Levey A.S \& Perpeira B. J.G. 2000. Late initiation of dialysis among women and ethnic minorities in the United States. Mexico: Journal of the American Society of Nephrology. 1046-6673/1112-2351.

Lants, P.M, Hause, J.S, Lepkowski J.,Williams D.R, Mero R.P. \& Chen J. 1998. Socioeconomic factors, health behaviours, and morality. Journal of the American Medical Association dalam Mac Arthur, CT. Research Network on Sosioeconomic Status and Health.

Ledebo et.al. 2001. Initiation of dialysis-opinion from an international survey: Report on the dialysis opinion symposium at the ERA-EDTA. Congress, 18 September 2000. Nephrol Dial Transplant, 16:1132-1138.

Lukman, 2013. Asuhan Keperawatan Gangguan Sistem Perkemihan. Jakarta : Salemba Medika.

Mc Donough, Duncan, William \& Hause. 1997. Income dynamics and adult mortality in the united states, 1972, through 1989. American Journal of public health dalam Mac Arthur, CT. Research $\mathrm{N}$ e t w o r k o n $\mathrm{S}$ o s i o e o n o m i c $\mathrm{Stat} \mathrm{t}$ a $\mathrm{nd} H$ e a $1 \mathrm{th}$. http:/www.macses,ucsf/Research/Social\%20Enviroment/notebook/economic.htm.

Murphy, F, Bryne G. 2009. Chronic kidney disease stages 4-5: Patient management: Brithish Journal of Cardiac Nursing, Vol4. No 2.

National Kidney Foundantion. 2000. K/DOQI Chlincal practice guideline for chronic kidney disease: Evaluations, Classification and stratification. 
Neyhart C, at al. 2010. A new nursing model for the care of patient with chronic kidney disease: The UNC Kidney center Nephrology Journal, Vol37, no 2.

Nissenson R.A., \& Fine R.N. 2002. Dialysis therapy, Third Edition. Hanley \& Belfos, Inc,Philadhelpia,New York.

Notoatmodjo, S. 2002. Metodologi penilitan kesehatan. Jakarta: PT. Rineka Cipta. .2003. Prinsip-prinsip dasar ilmu kesehatan masyarakat, cetakan-2. Jakarta: Rineka Cipta. .2003. Pendidikan dan perilaku kesehatan. Jakarta: Rineka Cipta.

Nursalam. 2016. Metodelogi Penelitian Ilmu Keperawatan Pendekatan Ilmiah. Jakarta : Salemba Medika.

Obrador, G.T., Ruthtazer, R., Arora, P., Kausz A.T., Pereira, B.J. 1999. Prevalence of and factors associated with suboptiomal care before iniation of dialysis in the United States, J Am Soc Nephrol. 10(8):1793-800.

Pernefri. 2003. Konsensus Dialisis Perhimpunan Nefrologi Indonesia. Jakarta .

Purnawan. 2008. Dukungan Keluarga. http:/wawan2507.wordpress.com/author/wawan2507.

Riskeda. 2013. Konsensus Dialisis Perhimpunan Nefrologi Indonesia. Jakarta. Diakses tanggal 19 Desember 2018.

Robbins, S.P. 2001. Organizational behavior: Concept, controversies and application; New Jersey, Prentice Hall.

Roderick P.J, Jones. C,Drey. N. 2002. Late referral for end stage renal disease: a region-wide survey in the south west of England. Nephrol Dial Transplant. 17:1252-1259.

Roina, E, \& Megawati. 2010. Faktor-faktor yang mempengaruhi Laju Filtrasi Glomerulus.

Rosanky. S.J, Clark, w.F, Eggers P, Glassock, RJ. 2009. Initiation of dialysis at higher GFRs: is the apparent rising tide of early dialysis harmful or helpful; international Society of Nephrology

Santo Imanuel Tonapa, Rina Kundre, Gresty Masi. Hubungan Dukungan Keluarga Dengan Keputusan Inisiasi Hemodialisis pada Penderita Penyakit Gagal Ginjal Kronik di Ruang Dahlia RSUP PROF. DR. R. D. KANDOU MANADO. Ejournal Keperawatan (e-kep) Volume 4 No 1, februari 2016. Diakeses tanggal 18 Desember 2018.

Shafer K, Rohrich B. 1999. The dilemma of renal replacement in patiens over 80 years of age. Nephrol Dial Transplant. 35:35-36.

Smeltzer \& Bare. 2008. Keperawatan Medical Bedah volume2. Jakarta: EGC.

Stanley, et al. 2007. Medication Adherence : many condition, a common problem.

Suharyanto, T. 2009. Asuhan Keperawatan Pada Klien dengan Gangguan Sistem Perkemihan. Jakarta : Trans Info Medika.

Sunarni. 2009. Hubungan antara Dukungan Keluarga dengan Kepatuhan Menjalani Hemodialisa pada Penderita Gagal Ginjal Kronik DI RSUD DR. MOEWARDI SURAKARTA. Jurnal Universitas Muhammadiyah Surakarta. Diakses pada 20 Desember 2018. 
Thomas, N. 2002. Renal Nursing (2nd ed). London United Kingdom: Elsevier Science.

Vassalotti. J.A, Weinstein L.G, Gannon M.R \& Brown W.W. 2006. Targeted screening and treatment of chronic kidney diseases, New York, USA: Dis Manage Health Outcomes 2006; 14(16): 341-352, 1173-8790/06/0006-0341/S39.95/0.

Walker, Abel \& Meyer. 2009. The role of the pre-dialysis nurse in New Zaeland, Renal Society of Australasia Jurnal// Marc 2010. Vol 6 no: 1-5. 